
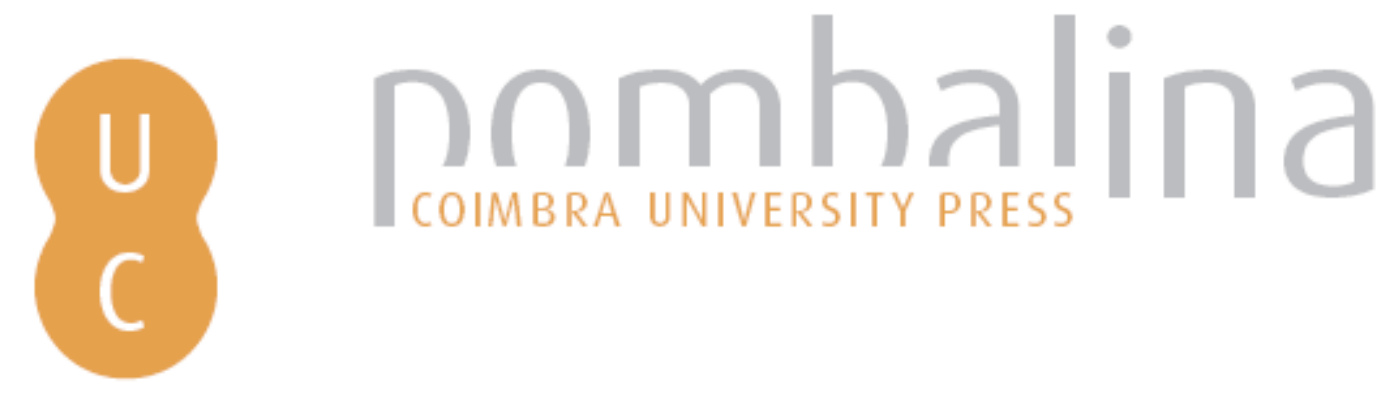

\title{
História empresarial: da monografia apologética ao instrumento de gestão estratégica
}

\author{
Autor(es): $\quad$ Mendes, José Amado \\ Publicado por: Imprensa da Universidade de Coimbra \\ URL \\ persistente: URI:http://hdl.handle.net/10316.2/31618 \\ DOI: $\quad$ DOI:http://dx.doi.org/10.14195/978-989-26-0199-1_20 \\ Accessed : $\quad$ 26-Apr-2023 11:51:40
}

A navegação consulta e descarregamento dos títulos inseridos nas Bibliotecas Digitais UC Digitalis, UC Pombalina e UC Impactum, pressupõem a aceitação plena e sem reservas dos Termos e Condições de Uso destas Bibliotecas Digitais, disponíveis em https://digitalis.uc.pt/pt-pt/termos.

Conforme exposto nos referidos Termos e Condições de Uso, o descarregamento de títulos de acesso restrito requer uma licença válida de autorização devendo o utilizador aceder ao(s) documento(s) a partir de um endereço de IP da instituição detentora da supramencionada licença.

Ao utilizador é apenas permitido o descarregamento para uso pessoal, pelo que o emprego do(s) título(s) descarregado(s) para outro fim, designadamente comercial, carece de autorização do respetivo autor ou editor da obra.

Na medida em que todas as obras da UC Digitalis se encontram protegidas pelo Código do Direito de Autor e Direitos Conexos e demais legislação aplicável, toda a cópia, parcial ou total, deste documento, nos casos em que é legalmente admitida, deverá conter ou fazer-se acompanhar por este aviso.

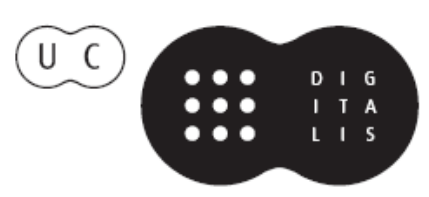


Maria Manuela Tavares Ribeiro

Coordenação

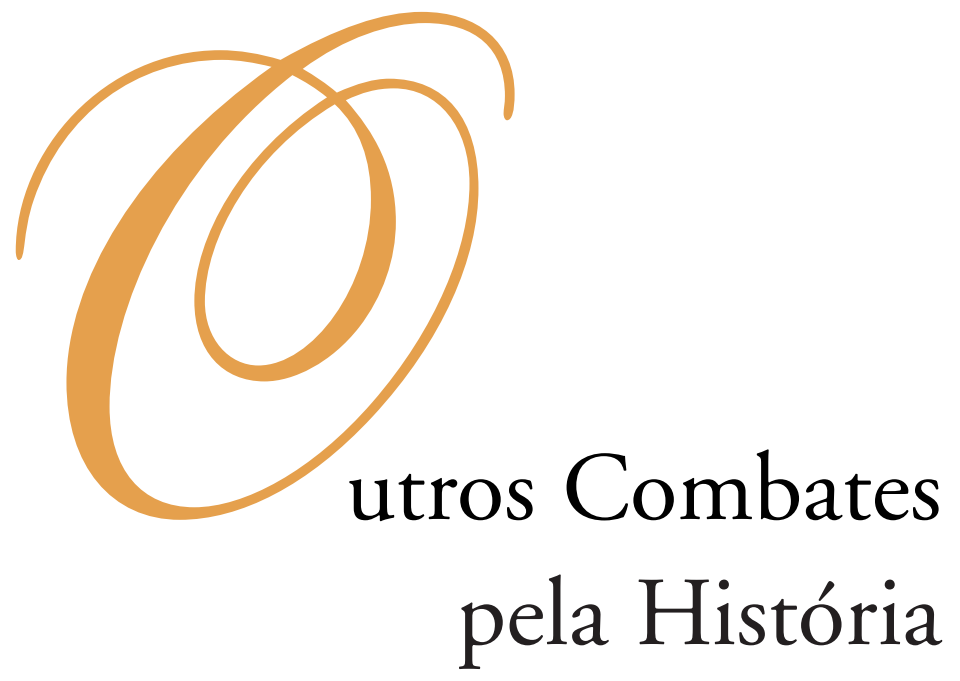




\section{COORDENAÇĀO EDITORIAL}

Imprensa da Universidade de Coimbra

Email: imprensauc@ci.uc.pt

URL: http://www.uc.pt/imprensa_uc

Vendas online: http://livrariadaimprensa.com

\section{CONCEPÇÃO GRÁFICA}

António Barros

\section{ORgANIZAÇĀO DOS TEXTOS}

Isabel Maria Luciano

Marlene Taveira

PRÉ-IMPRESSÃO

António Resende

Imprensa da Universidade de Coimbra

EXECUÇÃO GRÁFICA

SerSilito • Maia

ISBN

978-989-26-0041-3

DEPósito LEGAL

OBRA PUBLICADA COM O APOIO DE:

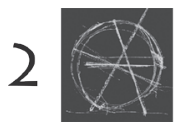

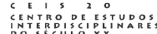

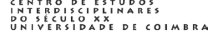

FCT Fundação para a Ciência e a Tecnologia

MINISTÉRIO DA CIÊNCIA, TECNOLOGIA E ENSINO SUPERIOR Portugal

Programa Operacional Ciência, Tecnologia, INOVAÇĀo DO QUADRo COMUNITÁRIO DE APOIO III

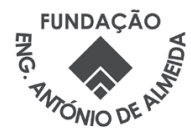

C JULHO 2010, IMPRENSA DA UNIVERSIDADE DE COIMBRA 
Maria Manuela Tavares Ribeiro

Coordenação

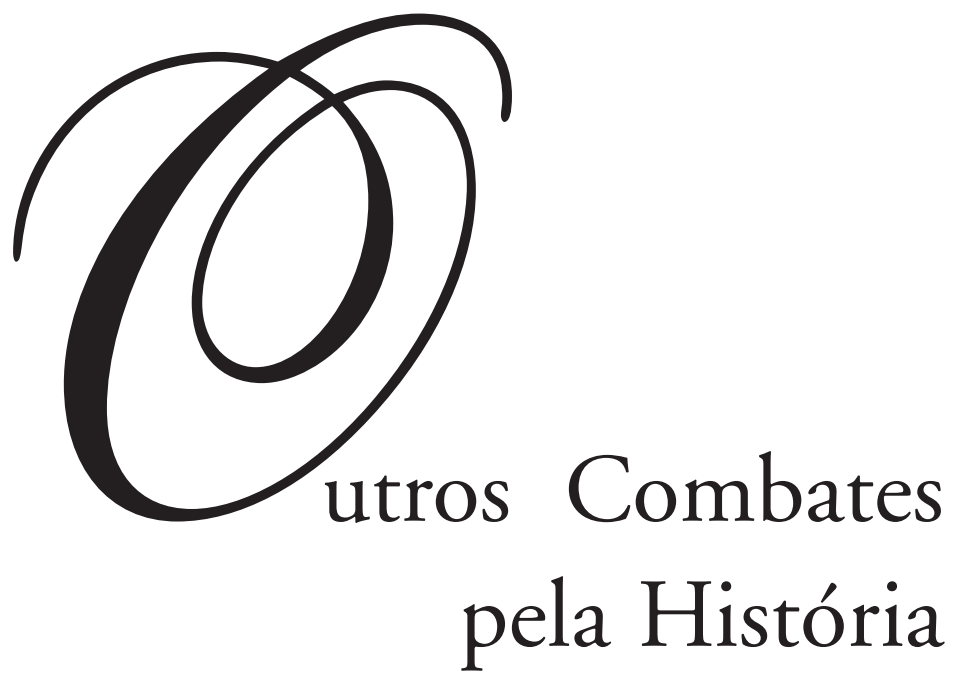

- colmbra 2010 
História e Organizaçôes

ECONÓMICAS E SOCIAIS 
José Amado Mendes

\section{História EMPRESARIAL: DA MONOGRAFIA APOLOGÉTICA AO INSTRUMENTO DE GESTÃo ESTRATÉGICA}

\section{Introdução}

A história empresarial apresenta-se hoje como uma das disciplinas históricas mais jovens e dinâmicas ${ }^{1}$. Aliás, a sua relevância advém, inclusive, da importância que assume actualmente a empresa. De facto, «com os Estados nacionais e as instituiçôes internacionais, ela é uma das mais poderosas realidades associativas da história contemporânea» ${ }^{2}$.

Em alguns países, a história empresarial já alcançou a devida maturidade e autonomizou-se, constituindo um campo específico de pesquisa, divulgação e ensino-aprendizagem. Noutros, continua ligada, como subdisciplina, à história económica. Todavia, mesmo nestas circunstâncias, muito tem contribuído não apenas para o enriquecimento da referida história como também para a sua actualização e revitalização, como já tive o ensejo de expor noutro trabalho ${ }^{3}$. Em qualquer dos casos, trata-se de uma temática digna de estudo e que carece de especial atenção.

Todavia, antes de prosseguir, convém esclarecer, afinal, o que é a história empresarial. Em primeiro lugar, note-se que ela apresenta "diversas caras», usando a

\footnotetext{
${ }^{1} \mathrm{O}$ texto que ora se publica, revisto e anotado, foi inicialmente apresentado numa conferência proferida no âmbito do Simpósio Internacional de Pós-Graduação em História da Universidade de São Paulo-Brasil (em 3 de Setembro de 2008) e no Colóquio Internacional «Outros Combates pela História», organizado na Universidade de Coimbra, pelo Centro de Estudos Interdisciplinares do Século XX-CEIS 20 (em 5 de Novembro de 2008).

2 Giulio Sapelli, «La construcción social e histórica de la empresa: para un nuevo modelo teórico», Francisco Comín e Pablo Martín Aceña (coords. da edição), La empresa en la Historia de España, Madrid, Ed. Civitas, 1996, p. 473-487 (tal como nas restantes citações, a partir de língua estrangeira, a tradução é da minha responsabilidade).

3 José Amado Mendes, «História das organizações na reabilitação da História Económica e Social», sep. das Actas do Colóquio Portugal - Brasil. Uma visão interdisciplinar do século XX. 2 a 5 de Abril de 2003, Coimbra, Quarteto/Ceis 20, 2003, pp. 133-148.
} 
expressão de Jesús M. ${ }^{a}$ Valdaliso, a propósito de algumas publicaçôes sobre assunto, vindas a lume em Espanha, alguns anos atrás ${ }^{4}$.

Por exemplo, se, em vez de história empresarial, falarmos de história das organizações - expressão mais abrangente e igualmente usada por certos autores —, aquela passa a referir-se também a um conjunto muito vasto de instituições que, não sendo propriamente empresas, com elas partilham muitas das suas características, em termos históricos, culturais, organizativos e de gestão. Recordo, por exemplo, organizaçôes sem fins lucrativos ${ }^{5}$, actualmente mais conhecidas por empresas dos «sectores sociais» ${ }^{6}$ : corporações de bombeiros, escolas, museus, associações, fundações e clubes desportivos.

Por outro lado, a história empresarial pode reportar-se ao estudo de casos - como uma espécie de biografia ou de prosopografia das empresas - neste caso, se incluir o estudo de várias empresas do mesmo tipo ou com características similares — ou à inserção e ao papel das empresas e dos empresários no desenvolvimento da economia, na evolução do capitalismo, nas formas de gestão, na sua relação com a estrutura e a escala empresarial, na linha das pesquisas desenvolvidas por Alfredo D. Chandler.

Pode ainda investigar-se a função das empresas no contexto das três revoluções industriais, perspectiva seguida na importante obra intitulada Creating modern capitalism. How entrepreneurs, companies, and countries triumphed in three Industrial Revolutions ${ }^{7}$.

Como já foi sublinhado, "a história empresarial pode entender-se como o estudo da empresa, segundo uma perspectiva histórica» ${ }^{8}$. Com efeito, "as origens, o crescimento e o rendimento da empresa como instituição são constitutivos da disciplina»?.

Obviamente que, empresários e gestores, como protagonistas principais da actividade empresarial, constituem igualmente objecto de estudo. Todavia, o que é válido para a história, em geral, é-o também, claramente, para a história das empresas. Trata-se de um processo em curso e não fechado.

Como esclarece Alan Robers, «não só não há escritos definitivos sobre o passado porque há sempre a possibilidade de que apareçam novos documentos, novas evidências, mas também (e isto é muito importante) porque o passado receberá novas interpretaçôes no futuro através das relações que os acontecimentos passados têm com os futuros. Com efeito, como o futuro está aberto, o passado também o está» ${ }^{10}$.

\footnotetext{
${ }^{4}$ Jesús M. a Valdaliso «Las diversas caras de la historia empresarial en España. Un comentario sobre algunas publicaciones recientes», Historia Industrial, 9, 1996, pp. 175-180.

5 Peter F. Drucker, As organizaçôes sem fins lucrativos (trad. do inglês), Lisboa, Difusão Cultural, 1994.

${ }^{6}$ David Bornstein, Como mudar o Mundo. Os empreendedores sociais e o poder de novas ideias (trad. do inglês), Lisboa, Estrela Polar, 2007.

7 Thomas K. McCraw (ed.), Creating Modern Capitalism. How Entrepreneurs, Companies, and Countries Triumphed in Three Industrial Revolutions, Harvard University Press, 2000.

8 Alan Roberts, «La teoria en la historia empresarial», Carmen Erro (dir.), Historia empresarial. Pasado, presente y retos de futuro, Barcelona, Ed. Ariel, 2003, p. 63.

${ }^{9}$ Idem, p. 61.

10 Idem, pp. 58-59.
} 


\section{Origem e evolução da história empresarial}

1. ${ }^{\circ}$ Período. A história empresarial já tem raízes profundas no tempo, podendo dizer-se que é quase tão antiga como as empresas, cuja importância e multiplicação coincidem com o desenvolvimento da economia moderna, desencadeada pela $1 .{ }^{\mathrm{a}}$ revolução industrial, a partir das últimas décadas do século XVIII. Recorrendo a um exemplo português, lembro que já Acúrsio das Neves - figura muito interessante e algo paradoxal, pois foi, simultaneamente, conservador em política e progressista em economia - , afirmava, em 1827:

«Uma História completa dos nossos estabelecimentos fabris, acompanhada das competentes aplicações dos princípios de Economia Política e da Administração Fiscal, seria um importante serviço feito ao Estado, tanto pela novidade e dificuldade da matéria, que os nossos antecessores deixaram intacta e confundida, como pelos muitos auxílios que dela se podem tirar» ${ }^{11}$.

Preocupado com a preservação das fontes, ao referir-se à informação que fornece sobre estabelecimentos industriais — particularmente relativa à Fábrica das Sedas do Rato, em Lisboa, e fábricas anexas - , acrescenta que o seu fim era «juntar memórias para que se não percam os materiais de que alguma pena mais feliz do que a minha se possa aproveitar para escrever a História dos nossos estabelecimentos de indústria» ${ }^{12}$.

Todavia, no século XIX e primeiras décadas do XX, só muito esporadicamente se estudaram as empresas. As escolas históricas então em voga — nomadamente a positivista e a metódica - e a própria cultura elitista, que então imperava, não favoreciam a eleição da realidade empresa como objecto de estudo. O que então interessava, salvo raras excepções, eram os eventos políticos e militares, a história diplomática ou a biografia das chamadas grandes figuras, com menosprezo pelo quotidiano, pelo trabalho, pela economia e pela tecnologia, ambiente no qual as empresas se movimentam. A cronologia e a datação precisa de determinados eventos, baseadas na exploração minuciosa de fontes escritas e inéditas, eram então exaustivamente analisados.

Mesmo a chamada escola dos Annales, a partir de 1929, não fomentou a história empresarial, pois estava mais voltada para os fenómenos de massa - o macro e o colectivo - , susceptíveis de serem quantificados, analisados em série e traduzidos em gráficos e quadros, já que o individual e o particular não se enquadravam no paradigma científico a que a ciência histórica aspirava.

Porém, a questão começava a interessar a alguns investigadores e a própria direcção daquela revista (então designada Annales d'Histoire Économique et Sociale, começada a publicar em Estrasburgo, em 1929) não lhe era indiferente, pois inseriu, logo em 1931, um artigo de Norman S. B. Gras ${ }^{13}$. Este autor que, entretanto, publicou outros trabalhos sobre a matéria, foi o primeiro a ocupar a cátedra de História Empresarial,

11 José Acúrsio das Neves, Obras completas, vol. 4: Memória económica-politica sobre a liberdade do comércio dos grãos com a sua aplicação às Ilhas dos Açores e outros escritos económicos, Porto, Ed. Afrontamento, s. d., p. 145.

12 J. Acúrsio das Neves, idem, p. 146.

$13 \mathrm{O}$ artigo, intitulado "Les affaires et $\mathrm{l}^{\prime}$ histoire des affaires», foi publicado nos Annales, t. III, n. ${ }^{\circ} 9$, 1931, pp. 5-10. 
criada na Harvard Business School, em 192714. Anos mais tarde, também o investigador francês Bertand Gille viria a interessar-se pelos arquivos das empresas, assunto sobre o qual publicou alguns trabalhos, nomeadamente uma obra, em $1958^{15}$.

Mas foi efectivamente nos Estados Unidos da América que a história empresarial começou a despertar maior atenção por parte de certos investigadores, nos anos de 1940-1950. Alguns escreviam sobre empresas, enquanto outros se dedicavam ao estudo de "gigantes industriais», como Henri Ford e John D. Rockefeller ${ }^{16}$.

Entretanto, em Portugal — assim como noutros países - , começava a aparecer, mais frequentemente, um género de história de empresa que viria a ter grande sucesso no futuro, isto é, a publicação de monografias, elaboradas no âmbito das comemorações de aniversários ou de outras datas marcantes.

Após a publicação da história da conhecida Fábrica de Porcelana Vista Alegre (que, aquando das comemorações do seu centenário, em 1924, além da respectiva História ${ }^{17}$, criou um interessante museu de empresa), em 1954, uma outra fábrica de cerâmica do distrito de Coimbra (Estrela de Alva, concelho de Penacova) publicava a sua história, ao comemorar o $50 .^{\circ}$ aniversário ${ }^{18}$. Como continua em actividade, recentemente editou a história do respectivo centenário, esta já elaborada segundo as normas académicas adequadas ${ }^{19}$.

2. ${ }^{\circ}$ Período (anos 1960-1980). Este período, de modo muito particular no mundo anglo-saxónico mas não só, ficou indelevelmente marcado pelo extraordinário contributo de Alfred D. Chandler que, em 1962, publicou Strategy and Structure. Seguiram-se-lhe, entres outras, as obras The Visible Hand (1977) e Scale and Scope $(1990)^{20}$.

Como já foi devidamente sublinhado, «o trabalho de Chandler permanece central para a história empresarial, mais notoriamente através das suas generalizações acerca da relação entre estratégia e estrutura, a distinção entre sectores centrais e periféricos e a função da grande empresa na gestão e na inovação. As suas generalizaçôes continuam a ser controversas e disputadas, mas ainda fornecem a estrutura central para a discussão neste imenso e rico campo de estudo» 21 .

${ }^{14}$ Carmen Erro (dir.), Historia Empresarial. Pasado, presente y retos de futuro, Barcelona, Ariel, 2003, p. 206.

15 Bertrand Gille, Les archives d'entreprises, Paris, Imp. Nationale, 1958.

16 C. Erro (dir.), op. cit., p. 207.

17 Theodoro Ferreira Pinto, A Fábrica da Vista Alegre. O Livro do seu Centenário. 1824-1924, Lisboa, Sociedade a Sociedade de Porcelana Vista Alegre, Ld. ${ }^{a}, 1924$.

18 Manuel Ayres Falcão Machado, Fábrica de Cerâmica Estrela de Alva. Meio século ao serviço da Economia Nacional (1904-1954), Tipografia Comercial, 1954 (2.a ed., 1993).

19 Paula Cristina Ferreira Silva, Cerâmica Estrela d'Alva. 100 anos de História. 1904-2004, São Paio do Mondego, Estrela de Alva. Prefácio e coordenação de José Amado Mendes, 2004.

${ }^{20}$ Alfred D. Chandler, La mano visible. La revolución en la dirección de la empresa norteamericana (trad. do inglês), Madrid, Ministerio de Trabajo y Seguridad Social, 1988; Escala y diversificación. La dinámica del capitalismo industrial (trad. do inglês), tomos I e II, Prensas Universitarias de Zaragoza, 1996.

${ }^{21}$ Franco Amatori e Geoffrey Jones (eds.), Business History around the World, Cambridge University Press, 2003, p. 3. 
Joseph Schumpeter, em meados do século XX, havia chamado a atenção para o papel decisivo da empresa e do empresário, na inovação e no desenvolvimento económico. Por sua vez, A. D. Chandler alerta para o papel do gestor profissionalizado, verdadeira "mão visível», substituindo assim a concepção tradicional, defendida por Adam Smith (em 1776), para quem as forças do mercado — isto é, a «mão invisível» ${ }^{22}$ desempenhavam papel crucial. Citemos o próprio Chandler:

"A mão visível da direcção substitui a mão invisível das forças do mercado, onde e quando a nova tecnologia e os mercados em expansão permitiram a circulação, sem precedentes históricos, de um elevado volume de mercadorias a uma grande velocidade, através dos processos de produção e de distribuição. A empresa moderna foi, pois, a resposta institucional ao rápido ritmo da inovação tecnológica e à crescente procura de consumo nos Estados Unidos, durante a segunda metade do século XIX» 23 . Deste modo, nos Estados Unidos da América, como sucessivamente noutros países desenvolvidos, a economia entrava numa nova fase, ou seja, no chamado "capitalismo de gestão».

Para além da marca chandleriana que impregnou a pesquisa, sobretudo nos países anglo-saxónicos, este período ficou também caracterizado por outros aspectos, como um certo impulso dado à história empresarial, consubstanciado na publicação de obras resultantes de estudos de caso, geralmente patrocinados pelas próprias empresas.

Em Portugal, várias entidades bancárias, entre outras, passaram desde então a dispor das respectivas histórias, especialmente comemorativas de certas datas (centenário, meio século, etc.). Lembro, por exemplo, o Banco Nacional Ultramarino (1964), o Banco de Portugal (1971) e o Banco Lisboa \& Açores (1972). Posteriormente, outros estudos de caso lhes sucederam até à actualidade - Banco Comercial Português, Montepio Geral, Banco Borges \& Irmão, Banco Espírito Santo, Caixa Geral de Depósitos - , apresentando-se este o sector como o mais dotado de histórias de empresa $^{24}$.

Se, em muitos casos, eram funcionários das próprias organizações que se encarregavam da tarefa - o que, não raro, condicionava a perspectiva de análise e induzia a elaboração de obras institucionais e um tanto laudatórias —, foi também por essa altura (meados de século passado) que começaram a ser solicitados historiadores profissionais para produzir monografias de empresas. Em certa sentido, pode afirmar-se que foi desde então que começaram a desenhar-se os dois modelos que ainda hoje perduram. Por um lado, a história institucional, mais ou menos apologética, na qual se narram, quase em exclusivo, os momentos gloriosos da empresa e a acção dos seus empresários, dirigentes e quadros mais destacados. Por outro, a história feita por

22 Adam Smith, Riqueza das Naçōes (trad. do inglês), vol. I, Lisboa, Fundação Calouste Gulbenkian, Fevereiro de 1981, p. 758.

23 Alfred D. Chandler, La mano visible. La revolución en la dirección de la empresa norteamericana (trad. do inglês), Madrid, Ministerio de Trabajo y Seguridad Social, 1988, p. 28.

${ }^{24}$ José Amado Mendes «La empresa bancaria en Portugal en el siglo XX. Evolución y estrategias», in Mario Cerutti, Empresas y grupos empresariales en América Latina, España y Portugal, Monterrey (México), Tendencias/Universidad Autónoma de Nuevo Léon/Universidade de Alicante, 2006, 350-372. Também publicado na revista Gestão e Desenvolvimento, 11, 1992, pp. 39-56. 
profissionais, inclusive académicos, cujo objectivo primordial é não elogiar ou enaltecer mas sobretudo compreender e explicar o percurso da empresa e dos agentes e intervenientes no processo, tendo em consideração os êxitos e os fracassos, os momentos altos mas também as vicissitudes, a gestão eficiente e de sucesso, mas igualmente a que viria a manifestar-se desadequada; isto é, a vida da empresa.

Para o efeito, foi necessário vencer alguma indiferença ou mesmo desconfiança da parte dos historiadores, relativamente ao papel da empresa na história, e dos próprios empresários/gestores, quanto à necessidade de abrir os respectivos arquivos a estranhos, cuja finalidade nem sequer compreenderiam muito bem. Resistência não menor provinha do lado de muitos historiadores que, por motivos ideológicos, colocavam reticências à «bondade» da empresa e do empresário que, por definição, se encontrariam do outro «lado da barricada».

Reportando-se a este comportamento - que também se verificou na história empresarial latino-americana —, notou o historiador de empresa colombiano, Carlos Dávila:

«Por várias décadas houve tabus poderosos que impediram muitos investigadores de se aproximar e estudar o empresariado, olhado por alguns como o seu "principal inimigo"; por outros como os "vende pátrias», «burguesia concupiscente» e "parasitária». Para muitos o empresariado sempre tem despertado - com razão — suspicácias. Estes preconceitos estiveram vinculados a processos económicos, políticos, ideológicos e sociais com que se debateu mais do que uma geração de académicos e intelectuais» 25 .

Nas décadas de 1950-1980, registaram-se, todavia, consideráveis progressos, desse ponto de vista. Assim, em 1985, o prestigiado e conhecido historiador francês, François Caron, no prefácio às actas do colóquio de história empresarial, publicadas sob o interessante título Memoire d'Avenir. L'Histoire dans l'Entreprise (Blois, 21-22 de Maio de 1985), escrevia:

«A empresa reconciliou-se com a História. Enquanto a maior parte dos historiadores tem rejeitado os modelos simplificadores para tentar captar, na sua desconcertante complexidade, as realidades sociais, e particularmente as da empresa, os empresários têm vindo a tomar consciência da necessidade de compreender o passado para construir o futuro. O problema hoje é não limitar essa reconciliação a uma petição de princípio. É preciso instaurar um diálogo que resulte numa troca de serviços, justificada por uma convergência de interesses. A História, numa palavra, tem necessidade da empresa, tanto como a empresa a tem da História» 26.

Data igualmente desta fase a questão do patrocínio, na sua relação com a dependência ou independência do investigador. Se, em muitos casos, pelo menos nas últimas décadas, a história de empresa pode ter servido como dissertação académica e ter sido mesmo elaborada à margem e sem a iniciativa da respectiva organização - o que, no presente, continua a suceder —, na maioria ela resulta das diligências ou mesmo da encomenda dos seus responsáveis.

25 Carlos Dávila L. de Guevara, Empresas e História en América Latina. Un balance historiográfico, Bogotá, TM Editores, 1996, p. XI.

${ }^{26}$ Maurice Hamon e Félix Torres, Memoire d'Avenir. L'Histoire dans l'Entreprise, Paris, Ed. Economica, 1987 , p. 8. 
Os objectivos podem ser muito diferentes: homenagear ou comemorar; conhecer as origens e a evolução da empresa; apreender as características essenciais da respectiva cultura, formada ao longo do tempo e, logo, em contexto histórico; fornecer aos proprietários/accionistas, dirigentes, gestores, técnicos, colaboradores, fornecedores e clientes, um conhecimento sólido acerca da identidade e das potencialidades da empresa, com vista a reforçar a sua imagem e credibilidade; proporcionar aos dirigentes e demais responsáveis pela gestão estratégica um meio que os auxilie a tomar as decisões mais adequadas, em cada situação; contribuir para um melhor conhecimento da história de determinada localidade, país ou região, recorrendo à exploração de fontes dos próprios arquivos empresariais.

Como conciliar os objectivos dos líderes da empresa com as exigências da investigação histórica — pautadas pelo rigor, a independência, o amor à verdade e a imparcialidade —, inclusive quando os encargos financeiros são suportados pela própria organização? Para alguns autores, embora de forma algo radical, patrocínio corresponde a parcialidade ou, o que ainda será mais grave, à tendência para narrar a história que mais favoreça a imagem da empresa.

Todavia, como já foi devidamente sublinhado, «o patrocínio [...] não é sinónimo de seguidismo nem de dependência, da mesma maneira que os investigadores que, nos começos do século XX, trataram de romper com os condicionamentos existentes, não poderiam classificar-se como tal. No fundo de tudo isso radica o profissionalismo do historiador que trata de realizar o seu trabalho, um conceito romântico mas que tem provado ser a única maneira de conseguir um ajuste entre qualidade e veracidade» 27 . Por outro lado, como também já foi observado, "o historiador escreve sempre para um público mais ou menos amplo (geral, académico, ideológico ou qualquer outro), sem que isso signifique que trabalhe mediatizado, condicionado ou subjugado» ${ }^{28}$.

Ainda nesta perspectiva, os nossos antecessores, por meados do século XX, já utilizaram um instrumento de enorme utilidade, que é o contrato escrito. Pela importância de que se reveste ainda hoje, merece que lhe dediquemos alguma atenção.

Num interessante e útil artigo de Christopher Castaneda, sob o título «Writing Contract Business History» ${ }^{29}$, são fornecidos diversos elementos sobre a matéria. Entre outros, o autor reporta-se ao contrato celebrado entre uma empresa norte-americana e historiadores, para elaborarem a respectiva história. Mais uma vez, N. S. B. Gras esteve envolvido na iniciativa, pois, em 1947, havia-se tornado presidente da Business History Foundation.

Tratava-se da Humble Oil \& Refining Company, uma subsidiária da Standard Oil of New Jersey (Exxon), cuja história viria a lume em 1959, sob o título: History of Humble Oil \& Refining Company. A Study in Industrial Growth ${ }^{30}$. O respectivo contrato viria a transformar-se, futuramente, no modelo a seguir, quando se optava por realizar contrato escrito. Dele constava, além do mais, o seguinte:

27 Cármen Erro e Francisco Javier Caspisteghi, «Empresarios e Historia Empresarial. Algunas claves para un mutuo acercamiento", C. Erro (dir.), op. cit., p. 185.

28 Idem, p. 186.

${ }^{29}$ Christopher J. Castaneda, "Writing Contract Business History», The Public Historian. A Journal of Public History, vol. 21, Winter, 1999, n. ${ }^{\circ}$ 1, pp. 11-29.

30 Nova Iorque, Harper \& Broders, 1959. 
A Humble concordava em:

- permitir o acesso, para efeitos de investigação, a todos os seus registos disponíveis;

- programar e facilitar entrevistas com empregados/colaboradores;

- autorizar visitas às infra-estruturas, instalações e equipamentos;

- obter o manuscrito [original] concluído para ser submetido à leitura e crítica de executivos e ex-executivos, para críticas e sugestóes;

- mas competia à Fundação/autores decidirem aquilo que, em última análise, deveria ser publicado 31 .

Como pode verificar-se pelos termos do contrato, era salvaguardado acesso a toda a informação da empresa - o que implicava a abertura dos arquivos para consulta, a visita às unidades industriais e a possibilidade de entrevistar colaboradores —, mas também a possibilidade de crítica e de apresentação de sugestôes, embora a última palavra pertencesse aos autores da obra e não à entidade visada e, simultaneamente, patrocinadora.

Não se deve, contudo, alimentar ilusões. Nem sempre estes casos terminam com um fim feliz, como sucedeu na pesquisa referenciada. Como bem lembra o autor do artigo citado, "por uma variedade de razóes [pelo menos nos Estados Unidos da América], cerca de $50 \%$ de todos os originais de história de empresas permanecem por publicar» 32 .

Em Portugal também temos exemplos destes últimos. Entre outros, lembro uma primeira biografia do Belmiro de Azevedo - empresário bem conhecido e indissociavelmente ligado à Sonae e à cadeia de grandes superfícies «Continente» —, que não chegou a entrar no prelo ${ }^{33}$, e um estudo de uma dinastia de empresários do Centro do País, cuja obra, intitulada Os Pinho de Vale de Cambra. Um caso de sucesso empresarial (da qual eu fui um dos co-autores, com Manuel Braga da Cruz e Manuel Ferreira Rodrigues, 1999), a qual, por razões a que fomos alheios, também não obteve autorização para vir a lume ${ }^{34}$.

\section{História das empresas na actualidade: o estado da arte}

Ao invés do que por vezes sucede em certos domínios da investigação, já dispomos de sínteses muito úteis, sobre a evolução da história empresarial, nas últimas décadas. Com efeito, para se obter uma visão de conjunto do desenvolvimento da disciplina, podemos recorrer a obras como:

\footnotetext{
31 C. J. Castaneda, op. cit., p. 16.

32 Idem, p. 17.

33 Segundo escreveu o próprio Eng. ${ }^{\circ}$ Belmiro de Azevedo, a primeira tentativa de elaboração e publicação da sua primeira biografia «foi um insucesso desagradável - e, por isso, o projecto (por falta de qualidade) não vingou" (Magalhães Pinto, Belmiro de Azevedo. História de Uma Vida, Lisboa, Círculo de Leitores, 2001, p. 394).

34 O Prof. Doutor Luís Valente de Oliveira dignou-se elaborar a "Apresentação" da obra, datada de 2 de Janeiro de 1998.
} 
- Business History Around the World (ed. Franco Amatori e Geoffrey Jones, 2003);

- Historia empresarial. Pasado, presente y retos de futuro (dir. Carmen Erro, 203);

- Empress y grupos empresariales en América Latina, España y Portugal (coord. Mario Cerutti, 2006);

- Empresas e Historia en América Latina. Un balance historiográfico (comp. Carlos Dávila L. de Guevara, 1996);

- British business history, 1720-1994 (John Wilson, 1995);

- La empresa en la Historia de España (coords. editoriais Francisco Comín e Pablo Martín Aceña, 1996);

- International Bibliography of Business History (Goodall et al., eds., 1997);

- «Empresas e empresários», Estudos Portugueses do século XX, n.o 4, 2004 (coords. José Amado Mendes e Alda Mourão Filipe) ${ }^{35}$.

Não sendo possível, nas presentes circunstâncias, condensar toda a informação contida nas obras acabadas de referenciar - além de que outras poderiam igualmente ser indicadas - , permito-me apenas destacar alguns traços mais distintivos da situação da história empresarial na actualidade, como campo de estudo, pesquisa, ensino e divulgação.

Em primeiro lugar, deve destacar-se o desenvolvimento considerável ao nível da investigação, patenteado pelas obras publicadas em grande número de países - livros de temática mais abrangente ou estudos de caso, revistas especializadas, artigos e comunicações —, bem como a organização de eventos dedicados à história empresarial, com a publicação das respectivas actas. Podemos referenciar, entre outros, encontros/colóquios organizados em França, no Japão, nos Estados Unidos (a série das Business History Conference, com um importante trabalho no domínio da pesquisa e da divulgação, começou em 1954 e prossegue, na actualidade), no México, no Brasil e em Portugal.

No Brasil, em 1991, realizou-se a Primeira Conferência Internacional de História de Empresas, que antecedeu o Congresso Brasileiro de História Económica, iniciado em 1993. A partir de então, os dois eventos, promovidos pela Associação Brasileira de Pesquisadores em História Económica, têm-se realizado conjuntamente. As actas tem vindo a ser publicadas com regularidade e, desde 1998, publica-se a revista História Económica \& História de Empresas ${ }^{36}$.

No que se refere a Portugal, além de proliferação de publicações, particularmente a partir da década de 1980, a Associação Portuguesa de História Económica e Social (APHES) tem dedicado atenção ao assunto, em alguns dos seus encontros anuais, designadamente nos seguintes:

- Évora (27 e 28 de Outubro de 1995), cujo XV Encontro integrou a História Empresarial em Portugal (as respectivas actas vieram a ser publicadas na conhecida revista Análise Social, vol. XXXI, n. ${ }^{\circ} 136 / 137,1996,2 .^{\circ}-3 .{ }^{\circ}$ );

- Aveiro (15 e 16 de Novembro de 2002), no qual, além de investigadores portugueses, participou o reputado especialista, Geoffrey Jones, um dos coordenadores da obra já citada, Business History around the World (2003).

\footnotetext{
35 As referências bibliográficas completas encontram-se no final do texto.

36 C. Erro (dir.), op. cit., p. 358.
} 
Entre as instituições universitárias cujos investigadores se têm dedicado à história empresarial, em Portugal, permito-me salientar a Faculdade de Letras da Universidade do Porto, a Faculdade de Letras da Universidade de Coimbra, a Universidade de Aveiro, o Instituto de Ciências Sociais, o Instituto Superior de Economia e Gestão e a Universidade Autónoma de Lisboa - UAL (através do Centro de Estudos de História Empresarial - CEHE), em Lisboa, e o Departamento de História da Universidade de Évora. Entre outros projectos que, por certo, se encontrarão em vias de concretização, lembro o da elaboração de um Dicionário de História Empresarial (em vários volumes), em curso, no âmbito do referido CEHE, da UAL.

No que concerne à especificidade das histórias de empresas nacionais, também a diversidade é notória, considerando os diferentes contextos: geográfico, social, económico, cultural, político e histórico. Assim, enquanto nos Estados Unidos a grande empresa e o desenvolvimento da liderança — desde a sua vertente patrimonial à do capitalismo de gestão —, sob a influência de A. Chandler e seus seguidores, foram amplamente estudadas, noutros países as preferências apontaram noutros sentidos.

Com efeito, na Grã-Bretanha, a perda de liderança do primeiro país industrial

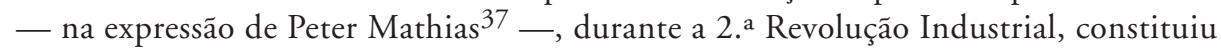
tema privilegiado; já na Alemanha, os historiadores centram-se mais nas grandes empresas, os aspectos técnicos e os novos produtos; por sua vez, no Japão, os estudos de caso têm sido privilegiados por maior número de investigadores, o mesmo se verificando em alguns países da Europa do Sul ${ }^{38}$. Aqui, questões deixadas em aberto por Chandler - por exemplo, a pequena e a média empresa, a empresa familiar e os distritos industriais - têm sido frequentemente objecto de estudo.

Para o investigador italiano Giulio Sapelli, de um modo geral, a história de empresa, como disciplina, afirmou-se sob a influência de duas tradições culturais:

a) norte-americana (influência de A. Chandler): desenvolvimento organizativo; crescimento tecnológico; dimensão dos mercados;

b) francesa: modelos culturais da acção directiva, alicerçando uma fértil trajectória analítica prosopográfica ${ }^{39}$.

Também a própria teoria e metodologia seguidas apresentam uma certa variedade, consoante o respectivo contexto e, inclusive, a formação de base do investigador. Quando este provém do campo da História - como se verifica, em muitos casos a tendência é para imprimir aos estudos um carácter mais humanista, valorizando os factores culturais na gestão e no percurso histórico da empresa. Se, ao invés, a sua formação resulta das áreas de Economia e Gestão, a tendência é para dar mais protagonismo a questões do foro económico propriamente dito, assim como à teoria explicativa da mesma matriz.

37 Peter Mathias, A primeira nação industrial. Uma história económica da Inglaterra, 1700-1914 (trad. do inglês), Lisboa, Assírio \& Alvim, s. d.

38 C. Erro (dir.), op. cit., p. 223 e ss.

39 G. Sapelli, «La construcción social e histórica de la empresa: para un nuevo modelo teórico», F. Comín e M. Aceña (eds.), op. cit., pp. 474-475. 
No primeiro caso, podemos falar da história empresarial tradicional, sem o recurso explícito às teorias económicas. No segundo, estamos perante o modelo da história empresarial como economia aplicada, recorrendo concretamente às teorias alicerçadas na Economia Neo-Institucional, a Nova Economia Industrial e a Economia dos custos de transacção ${ }^{40}$.

Em qualquer dos casos, como já foi recordado, a teoria é um meio e não um fim. A história empresarial é uma disciplina híbrida, situada entre a História, a Economia e a direcção estratégica de empresa. Nesse sentido, como afirma Robert Grand, referindo-se à direcção estratégica, "o propósito da História empresarial não é dar respostas, mas ajudar a compreender os problemas» 41 .

No que toca à história empresarial e ao seu papel, no sistema de ensino-aprendizagem e na formação de empresários, gestores e técnicos, a situação é igualmente diferenciada, não só entre países, mas também em relação a estabelecimentos do mesmo país. Todavia, um pouco por todo o Mundo - e salvo raras excepções —, há um défice considerável neste domínio.

Registam-se, todavia, excepçôes: certas universidades norte-americanas e britânicas, ou mesmo, a Colômbia — na América Latina — onde, já há alguns anos (2003), a disciplina de História empresarial existia em 20 universidades, dedicando-se-lhe, como docentes e investigadores, professores dos departamentos de História, de Sociologia e de Administração ${ }^{42}$.

Em muitos casos, a história empresarial, no âmbito do ensino, ainda não adquiriu autonomia em relação à história económica, pelo que não se pode falar de uma disciplina, mas de um capítulo ou de uma alínea. Noutros, apenas consta como disciplina opcional, em cursos de História, Economia e Gestão/Direcção de Empresas. Noutros ainda, a matéria é focada em seminários de pós-graduação, constituindo mesmo temática de teses de mestrado e de doutoramento.

Independentemente da situação, mais ou menos favorável, a este novo ramo de pesquisa, urge investir muito mais na área do ensino - de graduação e de pós-graduação, com destaque para este — , para que a história empresarial se torne uma janela aberta para a sociedade contemporânea, proporcionando uma melhor compreensão do Mundo e do contexto em que nos inserimos.

\section{Tendências e perspectivas futuras}

Regra geral, o historiador evita pronunciar-se sobre o futuro sentindo-se muito mais à-vontade ao debruçar-se sobre o passado, aliás, dentro da vocação normal da natureza das próprias disciplinas históricas. Embora ciente do acabado de referir, permita-se-me a ousadia de apontar algumas pistas e fazer determinadas sugestôes, com vista a conferir à história empresarial o lugar que ela, efectivamente, merece. Ao

\footnotetext{
40 Jesús M. ${ }^{a}$ Valdaliso "Las diversas caras de la historia empresarial en España. Un comentario sobre algunas publicaciones recientes», Historia Industrial, 1996, 9, p. 179.

41 C. Erro (dir.), op. cit., p. 39.

${ }^{42}$ Idem, pp. 362-363.
} 
assunto também se referem outros investigadores, por exemplo nos artigos intitulados "The Future of Business History». An Introduction» (Scranton e Horowitz, 1997) e «Business History and Beyond (Blackford, 1997), cuja leitura se recomenda.

4. 1. Enfoque e perspectivas temáticas. A avaliar pelos desenvolvimentos recentes da investigação, um dos filóes mais significativos passará, obviamente, pela elaboração de monografias ou estudos de casos, que permitam esclarecer as origens, o desenvolvimento e a caracterização da empresa/organização.

Para o efeito, importa analisar: o contexto socioeconómico e cultural; o meio envolvente - aspectos geográficos, existência ou não de matérias-primas, fontes de energia, acessibilidades, meios de transporte e comunicações — , os fundadores e gestores mais relevantes, sua formação, experiência e motivações; o capital, os recursos humanos, os meios técnicos, os produtos e o seu carácter inovador; o mercado e a concorrência; a expansão e, se for o caso, a internacionalização.

Todavia, como a empresa é uma realidade dinâmica, a investigação não pode incidir apenas no momento da fundação ou em fases críticas do respectivo processo, mas é necessário acompanhar e tentar compreender a sua evolução através dos tempos, investigando as formas como se foi dando resposta a novas situaçóes ou como se definiram estratégias consideradas como adequadas a cada situação.

Sob uma perspectiva tecnológica, não é suficiente atender apenas ao período de introdução de novas soluçôes técnicas; há que acompanhar a sua difusão e evolução, os resultados e as transformaçôes entretanto introduzidas, a fim de avaliar a eficácia dos investimentos efectuados. A própria gestão - centralizada ou descentralizada, conservadora ou agressiva, profissionalizada ou rotineira — à luz da relevância hoje atribuída à "mão visível», deve merecer igualmente atenção, o mesmo devendo suceder com a cultura de empresa e com a liderança implementada. O líder carismático — como foi entendido por Max Weber —, a profissionalização da actividade de gestão, a sucessão e as fusões e concentrações constituem, entre muitos outros, tópicos a esclarecer.

Porém, quando o objectivo ultrapassa o estudo individual de uma organização — isto é, o carácter biográfico — , para abranger todo um sector económico, a economia de uma localidade, região, país ou área mais vasta, tendo por ponto de partida a história empresarial, nesse caso interessa estudar, comparativamente, o conjunto das respectivas empresas, o que se assemelha à utilização do método prosopográfico, aplicado a grupos de indivíduos, com determinadas afinidades ${ }^{43}$.

Para questôes ainda mais abrangentes - evolução do capitalismo, capitalismo de gestão, revoluções industriais, globalização e outros —, também as empresas deverão ser perspectivadas de outro modo, não tanto em função de si próprias, mas antes na sua inter-relação com a realidade em estudo, devendo ser largamente utilizado o método comparativo. A propósito, mais uma vez se recorda a óptica seguida por A. Chandler.

43 Sobre a empresa em contexto regional e operando em rede, ver, por exemplo: José Luis García y Ruiz Carles Manera (dirs.), Historia Empresarial de España. Un enfoque regional en profundidad, Madrid, LID Editorial Empresarial, 2006; Judith Clifton et al., Redes e empresas en España. Una perspectiva teórica, histórica y global, Madrid, LID Editorial Empresarial, 2005. 
4. 2. Fontes e metodologia. Um dos legados mais relevantes da chamada nova história foi a revolução introduzida quanto ao conceito tradicional de fonte. Tradicionalmente, a fonte por excelência - e quase exclusiva - era o documento escrito (de preferência manuscrito) e inédito. A partir do alerta lançado pelos cultores da nova história - Marc Bloch e Lucien Fèbvre, F. Braudel, A. Silbert e Vovel, para nomear apenas alguns dos mais conhecidos - os materiais e as tecnologias, as estruturas e as paisagens, a literatura e a arte, as lendas e os mitos e até os próprios silêncios passaram a ser considerados como potenciais testemunhos históricos.

No que se refere à história das empresas e dos empresários, os arquivos empresariais continuam a desempenhar um papel central na investigação histórica da própria organização, mas não só (também na história local e regional, na história de um determinado ramo ou negócio, de familiares dos empresários, etc.). Mas, para além daqueles, há que tirar partido, por exemplo, de edifícios (mesmo desactivados ou já em ruínas) e equipamentos; máquinas, activas ou desactivadas; produtos e moldes, desenhos e plantas, fotografias, catálogos e papel timbrado; legislação e estatísticas, imprensa nacional e local; fontes orais e objectos simbólicos, desde a indumentária aos logótipos, para dar somente uns tantos exemplos.

Ainda do ponto de vista metodológico, à análise quantitativa - imprescindível, quando se trata de avaliar produção e transacções, abastecimento, consumos e salários, capital investido e dividendos —, há que acrescentar a descritiva/compreensiva, de modo a contemplar motivações e interesses, sensibilidades, comportamentos e, o que é muito importante, a verdadeira cultura da empresa.

Segundo certos autores, o pós-modernismo também deverá reflectir-se na história empresarial. Por um lado, ao recusar seguir modelos pré-estabelecidos, mas considerando cada empresa como um caso específico, com as suas especificidades e particularidades. Por outro, ao «desconstruir» o discurso de auto-elogio, elaborado no seio da própria empresa - através da história de empresa chamada institucional ou de outros materiais promocionais - pelos seus responsáveis ou por profissionais, a pedido daqueles.

Sobre esta questão, são de útil leitura as palavras de Alan Roberts, no capítulo dedicado à «Teoria na História Empresarial», na alínea: «Uma história empresarial pós-moderna?» ${ }^{44}$.

4. 3. Profissionalismo: competência, rigor e ética. Além do historiador/investigador profissional, académico ou com formação académica especializada, são por vezes solicitados, a elaborar monografias de empresas, outros profissionais, como publicitários, jornalistas, escritores, artistas, profissionais de marketing e de relações públicas, etc.

Estando ao serviço da empresa ou sendo contratados para executar essa tarefa, o que visam não é tanto efectuar uma investigação rigorosa, alicerçada em fontes e, tanto quanto possível, imparcial, mas sim apresentar produtos de carácter fundamentalmente promocional, com vista a reforçar, também por essa via, a respectiva imagem de marca.

Evidentemente que esses materiais são importantes e têm o seu lugar, mas não podem ser confundidos com histórias de empresas, elaboradas segundo as regras e a

${ }^{44}$ C. Erro (dir.), op. cit., pp. 64-68. 
metodologia da ciência histórica, em progressivo aperfeiçoamento desde, pelo menos, finais do século XVII até à actualidade.

De acordo com a teoria e a prática da pesquisa histórica, é necessário definir com precisão o tema a focar, delimitar o âmbito cronológico e geográfico, enunciar os objectivos a alcançar, formular hipótese de trabalho e esclarecer qual a metodologia a utilizar. Como não há compartimentos estanques na realidade socioeconómica e cultural, torna-se também necessário recorrer à interdisciplinaridade, recebendo contributos válidos de outros domínios do saber, desde a psicologia à sociologia, da estatística à contabilidade, da tecnologia à gestão.

As fontes a consultar devem ser diversificadas e exprimir várias sensibilidades e níveis de conhecimentos e de competências. Para o efeito, há que recorrer à documentação oficial e à privada - familiar ou mesmo pessoal, sem esquecer as regras de eventual sigilo, que poderão ter que ser usadas, em determinadas circunstâncias —, aos testemunhos orais de empresários, gestores e quadros técnicos, mas também operários e outros colaboradores, fornecedores e clientes, políticos e autarcas, com funções no meio onde a empresa está implantada ou opera.

Compete ao historiador, inclusivamente, destronar certos mitos, por muito arreigados que eles estejam. Um dos mitos mais vulgarizados é o de subvalorizar o activo com que o empresário se lançou na concretização de determinado projecto empresarial, empolando as carências e as limitações. Dir-se-á que o acto de heroicidade aparecerá, aos olhos da opinião pública, tanto mais extraordinário quanto mais humilde for o ponto de partida.

A questão foi muito bem analisada recentemente, por Eric Godelier, no artigo intitulado "Do You Have a Garage? Discussions of Some Myths about Entrepreneurship» 45. O autor dá exemplos vários de "gigantes» e "heróis de empresa», acerca dos quais foram mitificados aspectos relacionados com as suas origens modestas e a sua limitada formação académica, mas sem que tal os tenha impedido de alcançar o sucesso, nas empresas de referência que criaram. Refere, entre outros: Bill Hewlett e Dave Packard, Bill Gates e Andrew Carnegie, e Henri Ford, nos Estados Unidos da América; ou Louis Renault, Coco Chanel e François Pinault, em França.

Godelier, reportando-se à forma como Steve Jobs, o mítico fundador da Apple Macintosh, se tornou famoso, sublinha:

"Jobs transitou muito rapidamente do status social de estudante para o de empreendedor. Isto foi possível devido ao seu conhecimento e competência, adquiridos através da experiência prática no ramo». E acrescenta: "as mensagens implícitas são claras: a promoção social é baseada no mérito pessoal e em critérios democráticos; regras sociais e instituições não têm influência negativa no novo líder de negócios» 46 .

Obviamente que os mitos não deixarão de influenciar a história, mas, recorda o ainda o mesmo autor, "estórias não são mitos e mitos não são história ${ }^{47}$.

\footnotetext{
45 Eric Godelier «Do You Have a Garage? Discussions of Some Myths about Entrepreneurship», Business and Economic History. On-Line, 2007, vol. 5, p. 5-6 (http://www.thebhc.org/publications/BEHonline/2007/ godelier.pdf).

${ }^{46}$ E. Godelier, idem, p. 1-6 (http://www.thebhc.org/publications/BEHonline/2007/godelier.pdf).

${ }^{47}$ Idem, p. 12.
} 
Um outro mito bem conhecido na história empresarial é a indevidamente chamada "lei das três geraçôes», segundo a qual a empresa é criada pelo avô, o filho leva-a ao auge e o neto encerra-a ou leva-a à falência. Não obstante a cada vez menor longevidade média das empresas — que, em alguns países, não ultrapassa as três décadas —, não há provas de que se trate, efectivamente, de uma lei, pois o reduzido número de estudos de caso, nos vários países, não permite tirar tais ilações.

Além do rigor, a história empresarial deve igualmente ser impregnada de ética. Questões hoje na ordem do dia, como a corrupção e a globalização ${ }^{48}$, entre outras, não poderão deixar de ser contempladas, tal como a já referida cultura de empresa ${ }^{49}$.

\subsection{Para que serve a história empresarial? Em prol da utilidade da investigação} histórica, sem complexos. Antes de concluir, permita-se-me fazer algumas consideraçóes acerca da utilidade da investigação histórica, no que concerne à história empresarial. Até recentemente, era quase ofensivo perguntar para que serve a ciência, ramo do saber ou disciplina, particularmente na área das Humanidades.

Ao falar do assunto, vem-me geralmente à memória a resposta dada por esse grande brasileiro, homem de cultura, que foi Gladston Chaves de Melo. Interpelado pelo aluno, logo na primeira aula, que lhe perguntava para que servia a disciplina que ia leccionar — da área das Humanidades —, respondeu-lhe: "para nada». Em seguida, enumerou algumas das coisas mais maravilhosas da nossa vida, as quais, embora aparentemente não sirvam para nada, contribuem para nos tornar felizes.

Tradicionalmente, entendia-se que, em última análise, o estudo das Humanidades servia para tornar o homem mais culto e isso bastava. Contudo, no que à história diz respeito, desde há séculos que esta se revelou de utilidade, como meio de legitimação, factor de identidade, culto da memória ou forma de se obter um melhor conhecimento das raízes. No entanto, regra geral, essas finalidades não eram explicitadas e abertamente reconhecidas.

Hoje, porém, fala-se abertamente de uma história pública, história aplicada ou história serviço - como preferia chamar-lhe Jorge Borges de Macedo —, no âmbito da qual os conhecimentos e a competência na disciplina são expressamente utilizados para alcançar determinados objectivos.

A public history, nos Estados Unidos da América, é uma nova modalidade de história, que mobiliza associações, alimenta publicações periódicas de maior fôlego e, inclusive, já constitui matéria de cursos de graduação e pós-graduação, em cujo âmbito são elaboradas dissertações sobre a temática.

Trata-se de uma história destinada ao grande público - e não apenas a especialistas e académicos —, a qual poderá ter uma função relevante, nas empresas como na comunicação social, nos organismos governamentais e nas autarquias, nas associações

48 Geoffrey Jones e R. Daniel Wadhwani, «Entrepreneurial Theory and History of Globalization», Business and Economic History. On-Line, 2007, vol. 5, p. 1-26 (http://www.thebhc.org/publications/ BHEonline/2007/jonesandwadhwani.pdf).

${ }^{49}$ Heli Valtonen, «Does Culture Matter? Entrepreneurial Attitudes in the Autobiographies of Twenty-Century Business Leaders in Finland and the United States», Business and Economic History. On-Line, 2007, vol. 5, p. 1-24 (http://www.thebhc.org/publications/BEHonline/2007/valtonen.pdf). 
como nas fundações, nos museus como nas instituições dedicadas às indústrias da cultura, no turismo, com destaque para o turismo cultural. Escusado será acrescentar que contribui ainda para criar postos de trabalho, o que constitui uma premência no domínio das Ciências Humanas e Sociais.

No elenco curricular dos cursos acima referidos, é importante que, além das disciplinas que tradicionalmente os integram - ciências do âmbito das bibliotecas e dos arquivos, comunicação e informação, museologia e património —, a história empresarial tenha um lugar de relevo - a fim de preparar profissionais competentes na área -, dada a quase omnipresença da realidade empresa, na história contemporânea.

No já referido Colóquio realizado em Blois (França), em 1985, chamou-se a atenção dos participantes não só para a história da empresa, como para a história na empresa - o que, longe de constituir um jogo de palavras, significa duas realidades bem diferentes - , como aliás se infere do título do volume das respectivas actas. A história pode, efectivamente, ser de uma enorme utilidade na empresa, por exemplo, nos seguintes domínios:

- organização, utilização e preservação dos arquivos;

- instalação e gestão de museus, bem como estudo e salvaguarda de colecções e objectos de interesse na história da organização;

- resolução de questôes do foro administrativo ou mesmo do contencioso, quando for necessário exibir documentação útil para comprovar a titularidade de certos bens ou outras questões problemáticas;

- selecção de documentos, objectos, plantas ou desenhos de produtos antigos, a fim de serem utilizados pela publicidade, com vista a reforçar a credibilidade, alicerçada na experiência e nas provas dadas.

\section{Conclusão}

Como se destaca nas Actas do dito Colóquio, a história é «um fermento de identidade e de comunicação na empresa», constituindo os seus arquivos uma importante mais-valia. Na sua relação com a gestão, sublinha-se o papel da história como auxiliar da decisão na empresa ou, por outras palavras, como instrumento ao serviço da gestão estratégica. Aí se pode ler:

«Face à reconstrução espontânea do passado por parte dos actores da empresa [...], a História permite, com a ajuda da distância exterior trazida pelo historiador, reencontrar e compreender a realidade das coisas estratégicas. Contra uma perspectiva linear dos eventos, ela elabora uma contra-arqueologia sublinhando as inflexões significativas, as continuidades mas também as rupturas. Ela permite também estabelecer «cenários ao invés», a fim de captar a origem particular de uma estratégia que se prolongue no presente, com vista a compreender o contexto inicial, a manutenção e as achegas ulteriores. Instrumento de uma visão passada por definição, "profeta ao recuo", como se pode qualificá-lo, o historiador não evoca senão uma lucidez retrospectiva, pos-eventum, uma capacidade que lhe é própria para estabelecer sínteses retrospectivas. [...]». E continua: 
«Longe de ser pontual ou de estar confinada ao campo universitário, a história na empresa não cessa de demonstrar a sua utilidade, pelo que deverá enquadrar-se, embora sem se reduzir a essa vertente, na noção de história aplicada» ${ }^{50}$.

\section{BIBLIOGRAFIA}

AMATORI, Franco e JONES, Geoffrey (eds.), Business History around the World, Cambridge University Press, 2003.

BASTO, Theodoro Ferreira Pinto, A Fábrica da Vista Alegre. O Livro do seu Centenário. 1824-1924, Lisboa, Sociedade de Porcelana Vista Alegre, Ld. ${ }^{a}, 1924$.

BLACKFORD, Mansel G. (1997), «Business History and Beyond», Business and Economic History, vol. 26, n. ${ }^{\circ}$ 2, p. 283-289 (http://www.h-net.org/-business/bhcweb/publications/BEHprint).

Bornstein, David, Como mudar o Mundo. Os empreendedores sociais e o poder de novas ideias (trad. do inglês), Lisboa, Estrela Polar, 2007.

CASTANeda, Christopher J., «Writing Contract Business History» The Public Historian. A Journal of Public History, 1999 (Winter), vol. 21, n. ${ }^{\circ}$ 1, pp. 11-29.

Cerutti, Mario (coord.), Empresas y grupos empresariales en América Latina, España y Portugal, Monterrey (México), Tendencias/Universidad Autónoma de Nuevo Léon/Universidad de Alicante, 2006.

ChANDleR, Alfred D., La mano visible. La revolución en la dirección de la empresa norteamericana (trad. do inglês), Ministerio de Trabajo y Seguridad Social, 1988.

CHAndler, Alfred D., Escala y diversificación. La dinámica del capitalismo industrial (trad. do inglês), tomos I e II, Prensas Universitarias de Zaragoza, 1996.

CLIFTON, Judith et al., Redes e empresas en España. Una perspectiva teórica, histórica y global, Madrid, LID Editorial Empresarial, 2005.

Comín, Francisco e MARTín Aceña (eds.), La Empresa en la Historia de España. Editorial Civitas,1996.

DÁvila L. DE Guevara, Carlos (comp.), Empresa e Historia en América Latina. Un balance Historiográfico, Bogotá, TM Editores, 1996.

DruCKer, Meter F., As organizaçôes sem fins lucrativos (trad. do inglês), Lisboa, Difusão Cultural, 1994.

Erro, Carmen (dir.), Historia Empresarial. Pasado, presente y retos de futuro, Barcelona, Ariel, 2003.

GarCía, José Luis y CARLes MANera, Ruiz (dirs.), Historia Empresarial de España. Un enfoque regional en profundidad, Madrid, LID Editorial Empresarial, 2006.

GILLE, Bertrand, Les archives d'entreprises, Paris, Imp. Nationale, 1958.

GODELIER, Eric «Do You Have a Garage? Discussions of Some Mythes about Entrepreneurship», Business and Economic History. On-Line, 2007, vol. 5, p. 1-20 (http://www.thebhc.org/publications/BEHonline/ 2007/godelier.pdf).

Goodall, Francis et al., International Bibliography of Business History, Londres e Nova Iorque, Routledge, 1997.

GraS, Norman S. B., "Les affaires et l'histoire des affaires", Annales d'Histoire Économique et Sociale, 1997, t. III, n. ${ }^{\circ}$ 9, 1931, pp. 5-10.

${ }^{50}$ Maurice Hamon e Félix Torres Mémoire d'Avenir. L'Histoire dans l'Entreprise, Paris, Ed. Economica, 1987, 9, pp. 223-226. 
Hamon, Maurice e Torres, Félix Mémoire d'Avenir. L'Histoire dans l'Entreprise, Paris, Ed. Economica, 1987.

«História empresarial em Portugal», Análise Social, 1996, vol. XXI, n. 136-137, 2. - 3..

JONES, Geoffrey e WADHWANI, R. Daniel «Entrepreneurial Theory and History of Globalization», Business and Economic History. On-Line, 2007, vol. 5, pp. 1-26 (http://www.thebhc.org/publications/BHEonline/ 2007/jonesandwadhwani.pdf).

Machado, Manuel Ayres Falcão, Fábrica de Cerâmica Estrela de Alva. Meio século ao serviço da Economia

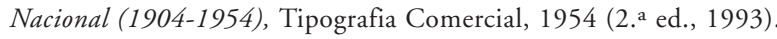

Mathias, Peter, A primeira nação industrial. Uma história económica da Inglaterra, 1700-1914 (trad. do inglês), Lisboa, Assírio \& Alvim, s. d.

MCCraw, Thomas K. (ed.), Creating Modern Capitalism. How Entrepreneurs, Companies, and Countries Triumphed in Three Industrial Revolutions, Harvard University Press, 2000.

MENDES, José Amado, "História das organizações na reabilitação da História Económica e Social», sep. das Actas do Colóquio Portugal-Brasil. Uma visäo interdisciplinar do século XX. 2 a 5 de Abril de 2003, Coimbra, Quarteto/CEIS 20, 2003, pp. 133-148.

Mendes, José Amado, "La empresa bancaria en Portugal en el siglo XX. Evolución y estrategias», in CERUTti, Mario, Empresas y grupos empresariales en América Latina, España y Portugal, Monterrey (México), Tendencias/Universidad Autónoma de Nuevo Léon/Universidad de Alicante, 2006.

MendeS, José Amado e FILIPE, Alda Mourão (coords.) «Empresas e Empresários», Estudos do Século XX, 2004, n. ${ }^{\text {4 }}$, Coimbra, Quarteto.

NeVES, José Acúrsio das, Obras completas, vol. 4: Memória económico-política sobre a liberdade do comércio dos grãos com a sua aplicação às Ilhas dos Açores e outros estudos económicos, Porto, Edições Afrontamento, s. d..

Roberts, Alan, «La teoria en la historia empresarial», Carmen Erro (dir.), Historia empresarial. Pasado, presente y retos de futuro, Barcelona, Ed. Ariel, 2003, pp. 57-80.

SAPELLI, Giulio, «La construcción social e histórica de la empresa: para un nuevo modelo teorico», Francisco Comín e Pablo Martín Aceña (coords. da edição), La empresa en la Historia de España, Madrid, Ed. Civitas, 1996, pp. 473-487.

SCranton, Philip e Horowitz, Roger, "The Future of Business History. An Introduction», Business and Economic History, 1997, vol. 26, n. ${ }^{\circ}$ 1, pp. 1-4 (http://www.h-net.org/ -business/bhcweb/publications/ BEHprint).

Silva, Paula Cristina Ferreira Cerâmica Estrela d'Alva. 100 anos de História. 1904-2004, São Paio do Mondego, Estrela d'Alva. Prefácio e coordenação de José Amado Mendes, 2004.

SMiTh, Adam, Riqueza das Nações (trad. do inglês), vol. I, Lisboa, Fundação Calouste Gulbenkian, Fevereiro de 1981 .

VALDALISO, Jesús M. ${ }^{a}$ «Las diversas caras de la historia empresarial en España. Un comentario sobre algunas publicaciones recientes", Historia Industrial, 1996, 9, pp. 175-180.

VALTONEN, Heli, «Does Culture Matter? Entrepreneurial Attitudes in the Autobiographies of Twenty-Century Business Leaders in Finland and the United States», Business and Economic History. On-Line, 2007, vol. 5, p. 1-24 (http://www.thebhc.org/publications/BEHonline/2007/valtonen.pdf).

Wilson, John F., British business history, 1720-1994, Manchester University Press, 1995. 

Série

Documentos

Imprensa da Universidade de Coimbra

Coimbra University Press

2010

- U

C • 